06.5;08.2

\title{
Низкотемпературный рост кубической фазы CdS методом атомно-слоевого осаждения на гибридных подложках $\mathrm{SiC} / \mathrm{Si}$
}

\author{
() С.А. Кукушкин ${ }^{1,2}$, А.В. Осипов ${ }^{1, \uparrow, ~ А . И . ~ Р о м а н ы ч е в ~}{ }^{3}$, И.А. Касаткин ${ }^{3}$, А.С. Лошаченко \\ ${ }^{1}$ Институт проблем машиноведения РАН, Санкт-Петербург, Россия \\ ${ }^{2}$ Санкт-Петербургский политехнический университет Петра Великого, Санкт-Петербург, Россия \\ ${ }^{3}$ Санкт-Петербургский государственный университет, Санкт-Петербург, Россия \\ ๑ E-mail: andrey.v.osipov@gmail.com
}

Поступило в Редакцию 14 июля 2020 г.

В окончательной редакции 14 июля 2020 г.

Принято к публикации 22 июля 2020 г.

Разработан новый метод эпитаксиального роста пленок сульфида кадмия (CdS) в метастабильной кубической фазе на подложках кремния с буферным слоем эпитаксиального карбида кремния путем атомно-слоевого осаждения. Данная фаза $\mathrm{CdS}$ достигается за счет низкой температуры роста $\left(\sim 180^{\circ} \mathrm{C}\right)$. Идентификация кубической фазы выполнена как с помощью дифракции рентгеновских лучей, так и методом спектральной эллипсометрии за счет того, что основной пик поглощения света $\mathrm{CdS}$ в гексагональной фазе расщеплен на два пика: 4.9 и $5.4 \mathrm{eV}$, а в кубической фазе является нерасщепленным (вырожденным): $5.1 \mathrm{eV}$.

Ключевые слова: сульфид кадмия, карбид кремния, гетероструктуры, метод атомно-слоевого осаждения, диэлектрическая проницаемость, эллипсометрия.

DOI: 10.21883/PJTF.2020.21.50186.18466

Как известно, сульфид кадмия (CdS) является прямозонным полупроводником с шириной зоны $\sim 2.4 \mathrm{eV}$, использующимся во многих приложениях микроэлектроники, связанных с солнечными батареями, фотоэлектрическими преобразователями, лазерами и т.д. [1]. $\mathrm{CdS}$ выращивается многими способами и на различных подложках [2-4]. Для интеграции в отлично развитую кремниевую электронику актуально выращивать слои $\mathrm{CdS}$ на кремнии, однако $\mathrm{CdS}$ вступает в химическую реакцию с Si с образованием аморфного сульфида кремния (SiS), который существенно ухудшает полупроводниковые свойства $\mathrm{CdS}$ [2]. Поэтому в работе [2] был разработан способ получения эпитаксиального слоя $\mathrm{CdS}$ на $\mathrm{Si}$ с буферным слоем $\mathrm{SiC}$ толщиной $\sim 20-100 \mathrm{~nm}$, который предохраняет $\mathrm{CdS}$ от химической реакции с $\mathrm{Si}$, но в то же время обеспечивает качественную эпитаксию слоя CdS. В подавляющем большинстве методов (в том числе методе испарения-конденсации [2]) $\mathrm{CdS}$ растет в гексагональной фазе, которая чуть более выгодна энергетически, чем кубическая фаза. Однако для ряда приложений желательно получать полупроводниковые слои в метастабильной кубической фазе, например для того, чтобы избежать негативного влияния пьезоэлектрического поля из-за упругих напряжений в эпитаксиальных слоях. За несколько десятилетий исследований было установлено несколько факторов, приводящих к появлению кубической фазы $\mathrm{CdS}$, в частности использование в качестве подложки $\operatorname{InP}(110)$ [4], а также существенное понижение температуры роста [5], что за счет кинетических эффектов приводит к появлению метастабильной фазы. К сожалению, оба способа имеют свои недостатки. В первом случае исключается интеграция с кремниевой электроникой, во втором резко падает скорость роста, что делает затруднительным получение $\mathrm{CdS}$ кубической фазы $(c-\mathrm{CdS})$ хотя бы $100 \mathrm{~nm}$ толщины. Цель данного исследования - разработать новый способ получения $c$-CdS на гибридных подложках $\mathrm{SiC} / \mathrm{Si}$, т. е. на подложках $\mathrm{Si} \mathrm{c} \mathrm{тонким} \mathrm{буферным} \mathrm{слоем} \mathrm{SiC}(\sim 20-100 \mathrm{~nm})$, методом атомно-слоевого осаждения (atomic layer deposition, ALD) [6], который обеспечивает приемлемую скорость роста $c$-CdS при низких температурах.

Кубическую фазу $c$-CdS предлагается получать за счет химической реакции между диметилкадмием $\left(\mathrm{Cd}\left(\mathrm{CH}_{3}\right)_{2}\right)$ в паровой фазе и газообразным сероводородом $\left(\mathrm{H}_{2} \mathrm{~S}\right)$

$$
\mathrm{Cd}\left(\mathrm{CH}_{3}\right)_{2}+\mathrm{H}_{2} \mathrm{~S}=\mathrm{CdS}+2 \mathrm{CH}_{4} \uparrow .
$$

Термодинамический анализ показывает, что оптимальная температура данной реакции находится в диапазоне $100-180^{\circ} \mathrm{C}$. При более высоких температурах становится существенным выделение углерода в фазе графита. При более низких температурах ухудшается диффузия атомов. Синтез пленок $c$-CdS методом атомно-слоевого осаждения проводился на установке „Наносерф“ (производство ООО „Наноинженерия““, Россия). Режим роста пленок „слой за слоем“ обеспечивался проведением циклов реакций поочередной обработки поверхности подложки газообразными реагентами с промежуточным удалением продуктов реакции и избытка реагентов. В качестве подложек использовались пластины $\mathrm{SiC} / \mathrm{Si}$ различной ориентации, полученные методом замещения атомов, т.е. за счет реакции замещения между подложкой $\mathrm{Si}$ и монооксидом углерода в газообразном состоянии

$$
2 \mathrm{Si}+\mathrm{CO}=\mathrm{SiC}+\mathrm{SiO} \uparrow .
$$




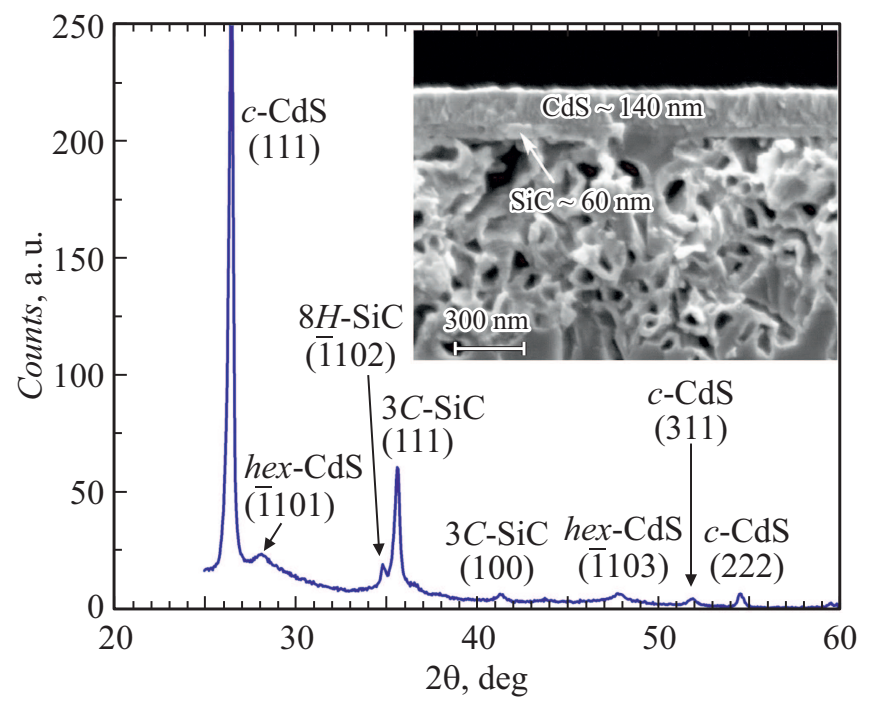

Рис. 1. Дифрактограмма рентгеновских лучей образца $\mathrm{CdS} / \mathrm{SiC} / \mathrm{Si}(111)$. На вставке приведено изображение среза образца $\mathrm{CdS} / \mathrm{SiC} / \mathrm{Si}(111)$, полученное с помощью растрового электронного микроскопа. Под слоем $\mathrm{SiC}$ видны поры и пустоты в объеме $\mathrm{Si}$, частично заполненные $\mathrm{SiC}$.

Технологические детали этого процесса приведены в обзорах $[7,8]$. Синтез $c$-CdS проводился при температуре $180^{\circ} \mathrm{C}$. Пары диметилкадмия и газообразный сероводород подавались поочередно в реактор в потоке инертного газа при пониженном давлении $\left(2 \cdot 10^{3} \mathrm{~Pa}\right)$, время напуска реагентов составляло от 10 до $50 \mathrm{~ms}$ с промежуточной продувкой реактора инертным газом при давлении $6 \cdot 10^{3} \mathrm{~Pa}(7-10 \mathrm{~s})$. В результате проведения каждого цикла таких обработок на поверхность подложки наносился слой $\mathrm{CdS}$ толщиной $\sim 0.12 \mathrm{~nm}$. Толщина синтезируемой пленки определялась количеством циклов таких обработок и составляла $100-150 \mathrm{~nm}$ за время 2-4h.

Эксперименты показали, что фаза $c$-CdS растет при использовании данного метода на гибридных подложках любой ориентации, т.е. $\mathrm{SiC} / \mathrm{Si}(111), \mathrm{SiC} / \mathrm{Si}(110)$, $\mathrm{SiC} / \mathrm{Si}(100)$, но эпитаксиальное качество кристаллической структуры получалось лишь на подложках $\mathrm{SiC} / \mathrm{Si}(111)$. Возможно, это связано с тем, что при росте на $\mathrm{Si}(111)$ происходит направленная эпитаксия $3 C-\mathrm{SiC}$ в направлении именно $\langle 111\rangle$ [7], тогда как при росте на $\mathrm{Si}(100)$ и $\mathrm{Si}(110)$ механизм роста $\mathrm{SiC}$ становится иным, что приводит к ухудшению качества $\mathrm{SiC}$ [8]. На рис. 1 приведена дифрактограмма рентеновских лучей образца $\mathrm{CdS} / \mathrm{SiC} / \mathrm{Si}(111)$, полученная на дифрактометре Bruker D8 Discover в излучении $\mathrm{Cu} K_{\alpha}$. Видно, что преимущественный рост $\mathrm{SiC}$ был именно в направлении $\langle 111\rangle$, причем рос в основном кубический политип $3 C$-SiC. Тем не менее в образце присутствует незначительная доля гексагонального полуполярного $8 H$-SiC (грань (1102)). Из дифрактограммы, представленной на рис. 1 , видно, что кубический $c-\mathrm{CdS}$ рос эпитаксиально, т.е. преимущественно в направлении $\langle 111\rangle$. В незначительной доле присутствует также грань $c$ - $\mathrm{CdS}(311)$. Помимо кубической присутствует также в малом количестве и гексагональная фаза $h e x-\mathrm{CdS}$ (грани (1101) и (1103)). На вставке к рис. 1 приведено изображение среза образца $\mathrm{CdS} / \mathrm{SiC} / \mathrm{Si}(111)$, выращенного методом $\mathrm{ALD}$ при температуре $180^{\circ} \mathrm{C}$, полученное с помощью растрового электронного микроскопа. Слой $c$-CdS имеет толщину около $140 \mathrm{~nm}$. Под слоем карбида кремния толщиной $60 \mathrm{~nm}$ отчетливо видны поры и пустоты в объеме подложки кремния, частично заполненные $\mathrm{SiC}$ [7], которые образовались в результате реакции замещения (2). Их образование напрямую связано с релаксацией упругих напряжений на границе раздела $\mathrm{SiC} / \mathrm{Si}$ и отсутствием на ней дислокаций несоответствия решеток [7], на качество $\mathrm{SiC}$ они не влияют. На рис. 2 изображен типичный рамановский спектр образца $c$-CdS/3C-SiC/Si(111), выращенного методом ALD. Отметим, что помимо единственной линии первого порядка $c$-CdS $1 \mathrm{LO}\left(303 \mathrm{~cm}^{-1}\right)$, отвечающей продольным оптическим колебаниям атомов, отчетливо видна соответствующая линия второго порядка $2 \mathrm{LO}\left(605 \mathrm{~cm}^{-1}\right)$. Направление колебаний атомов серы в $c$-CdS, соответствующих линии 1LO, рассчитанных методами квантовой химии, показано на вставке к рис. 2. Поскольку ширина прямой запрещенной зоны $c$-CdS $(2.4 \mathrm{eV})$ чуть больше энергии излучения лазера $(532 \mathrm{~nm} \sim 2.33 \mathrm{eV})$, на рамановском спектре также видны линии как $\mathrm{Si}$, так и $\mathrm{SiC}$ (рис. 2). На рис. 3, $a$ представлена зависимость псевдодиэлектрической функции от энергии фотонов образца $c$-CdS/3C-SiC/Si(111), измеренная на эллипсометре M-2000D J.A. Woollam с вращающимся компенсатором в диапазоне энергий фотонов $0.7-6.4 \mathrm{eV}$. Исследования показали, что для теоретического описания спектров, приведенных на рис. $3, a$, достаточно

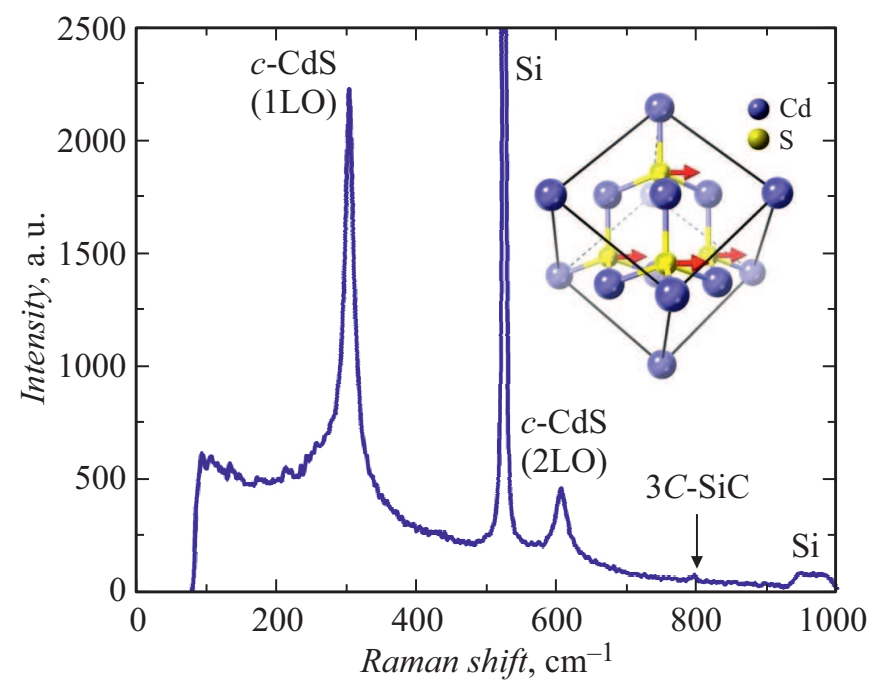

Рис. 2. Рамановский спектр образца $c-\mathrm{CdS} / 3 C-\mathrm{SiC}(111) / \mathrm{Si}(111)$. На вставке показаны колебания атомов серы в $c-\mathrm{CdS}$, отвечающие линии $1 \mathrm{LO}\left(303 \mathrm{~cm}^{-1}\right)$. 

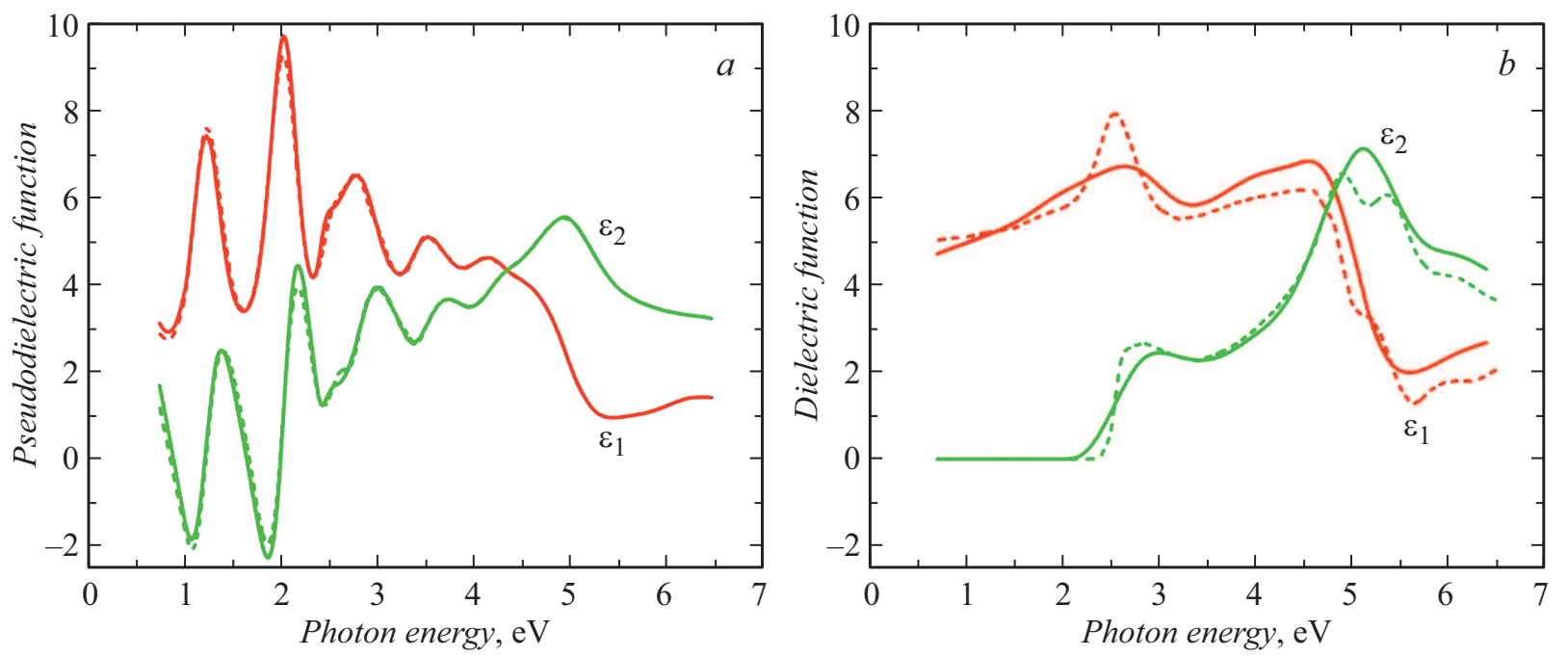

Рис. 3. Зависимости вещественной $\varepsilon_{1}$ и мнимой $\varepsilon_{2}$ частей диэлектрической проницаемости от энергии фотонов. $a-$ образец $c-\mathrm{CdS} / 3 C-\mathrm{SiC}(111) / \mathrm{Si}(111)$ : экспериментальная кривая (сплошная линия) и теоретическая кривая с толщиной слоя $c$-CdS $130 \mathrm{~nm}$ (штриховая линия). $b-c$-CdS, аппроксимация сплайнами с шагом $0.3 \mathrm{eV}$ (сплошная линия) и hex-CdS (по данным работы [2]) (штриховая линия). Видно, что на зависимости $\varepsilon_{2}(E) \mathrm{CdS}$ в кубической фазе присутствует нерасщепленный пик $5.1 \mathrm{eV}$, в гексагональной - расщепленный $(4.9$ и $5.4 \mathrm{eV})$.

использовать простейшую однослойную эллипсометрическую модель [9], состоящую из исходной гибридной подложки 3C-SiC $(111) / \mathrm{Si}(111)$, спектр которой был измерен заранее, и слоя CdS. Как принято в классической спектральной эллипсометрии, сверху слоя $\mathrm{CdS}$ учитывается слой шероховатости, представляющий собой смесь атомов $\mathrm{CdS}$ и пустот [9], между слоями $\mathrm{CdS}$ и $\mathrm{SiC}$ в модели используется промежуточный слой, состоящий из смеси атомов $\mathrm{CdS}$ и $\mathrm{SiC}$ [9]. Такая однослойная модель адекватно описывает образцы $c-\mathrm{CdS} / 3 C-\mathrm{SiC} / \mathrm{Si}(111)$ (рис. 3,a) и позволяет измерить толщину слоя $c$-CdS. Для образца со спектром, показанным на рис. $3, a$, она равна $130 \mathrm{~nm}$. Кроме того, в рамках данной модели можно извлечь информацию о диэлектрической проницаемости $c$-CdS, полученного методом ALD, аппроксимируя диэлектрическую проницаемость сплайнами с постоянным шагом [9]. Увеличение шага аппроксимации уменьшает точность, чрезмерное уменьшение шага приводит к росту неустойчивости аппроксимации. Для данной серии экспериментов оптимальным шагом является ша $0.3 \mathrm{eV}$. Результаты расчетов диэлектрической проницаемости $c$-CdS приведены на рис. 3,b. Там же для сравнения представлена диэлектрическая проницаемость гексагонального $\mathrm{CdS}$, выращенного на такой же подложке при температуре $650^{\circ} \mathrm{C}$ [2] (скорость роста была равна $300 \mathrm{~nm}$ за $4 \mathrm{~s}$ ).

Отметим, что эллипсометрия является простым и надежным методом распознавания политипов прямозонных полупроводников, таких как $\mathrm{CdS}$. Второй по счету пик $E_{1}$ спектра поглощения $\mathrm{CdS}$, отвечающий максимуму мнимой части диэлектрической проницаемости $\varepsilon_{2}$ при энергии фотонов $5.1 \mathrm{eV}$ (рис. $3, b$ ), в гексагональной фазе расщепляется на два пика [3] с энергиями 4.9 и
$5.4 \mathrm{eV}$ соответственно (рис. $3, b$ ). Симметрия кубической фазы запрещает подобное расщепление, что кардинально отличает кубическую фазу от гексагональной [3]. Tо, что у $\varepsilon_{2}(E)$ образцов, полученных методом ALD при температуре $180^{\circ} \mathrm{C}$, пик вблизи $5 \mathrm{eV}$ всегда только один, видно из рис. 3, $a$ без какого-либо эллипсометрического моделирования. Напротив, у всех образцов $\mathrm{CdS}$, полученных методом испарения-конденсации при температуре $650^{\circ} \mathrm{C}$, пиков всегда два [2].

Таким образом, в работе предложен метод получения слоев кубического $\mathrm{CdS}$ на подложках кремния $\mathrm{Si}(111)$ с буферным слоем $\mathrm{SiC}$ путем атомно-слоевого осаждения за счет химической реакции (1). Кубическая фаза $\mathrm{CdS}$ достигается за счет низкой температуры роста $\left(\sim 180^{\circ} \mathrm{C}\right)$. Выполнен эллипсометрический анализ образцов $c-\mathrm{CdS} / 3 C-\mathrm{SiC}(111) / \mathrm{Si}(111)$ и определена зависимость от энергии диэлектрической проницаемости $c$-CdS, выращенного методом ALD.

\section{Благодарности}

Исследования проводились с использованием оборудования уникальной научной установки „Физика, химия и механика кристаллов и тонких пленок“ ФГУП ИПМаш РАН (Санкт-Петербург) и научного парка СПбГУ (ресурсный центр „Инновационные технологии композитных наноматериалов“, Междисциплинарный ресурсный центр по направлению „Нанотехнологии“ и „Рентгенодифракционные методы исследования““).

\section{Финансирование работы}

Работа выполнена в рамках проекта Российского научного фонда № 20-12-00193. 


\section{Конфликт интересов}

Авторы заявляют, что у них нет конфликта интересов.

\section{Список литературы}

[1] Handbook of photovoltaic science and engineering / Eds A. Luque, S. Hegedus. Chichester: John Wiley and Sons, 2003. $1165 \mathrm{p}$.

[2] Антипов В.В., Кукушкин С.А., Осипов А.В. // ФТТ. 2016. T. 58. B. 3. C. $612-615$.

http://journals.ioffe.ru/articles/viewPDF/42829

[3] Cardona M. // Phys. Rev. 1965. V. 140. P. A633-A637.

DOI: 10.1103/PhysRev.140.A633

[4] Rossow U., Werninghaus T., Zahn D.R.T., Richter W., Horn K. // Thin Solid Films. 1993. V. 233. P. 176-179. DOI: 10.1016/0040-6090(93)90084-3

[5] Nagai T., Kanemitsu Y., Ando M., Kushida T., Nakamura S., Yamada Y., Taguchi T. // Phys. Status Solidi B. 2002. V. 229. P. 611-614. DOI: 10.1002/1521-3951 (200201)229:1<611::AID-PSSB611>3.0.CO;2-3

[6] Малыгин А.А., Малков А.А., Соснов Е.А. // Изв. АН. Сер. хим. 2017. № 11. С. 1939-1962.

DOI: $10.1007 / \mathrm{s} 11172-017-1971-9$

[7] Kukushkin S.A., Osipov A.V. // J. Phys. D.: Appl. Phys. 2014. V. 47. P. 313001. DOI: $10.1088 / 0022-3727 / 47 / 31 / 313001$

[8] Кукушкин С.A., Осипов А.В., Феоктистов Н.А. // ФТТ. 2014. T. 56. B. 8. C. $1457-1485$.

http://journals.ioffe.ru/articles/viewPDF/40674

[9] Spectroscopic ellipsometry for photovoltaics. V. 1. Fundamental principles and solar cell characterization / Eds H. Fujiwara, R.W. Collins. Cham: Springer, 2018. 594 p.

DOI: $10.1007 / 978-3-319-75377-5$ 